\title{
Redox regulation of anoikis: reactive oxygen species as essential mediators of cell survival
}

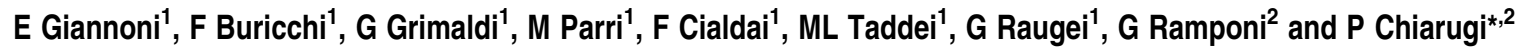

Proper attachment to the extracellular matrix (ECM) is essential for cell survival. The loss of integrin-mediated cell-ECM contact results in an apoptotic process termed anoikis. However, mechanisms involved in regulation of cell survival are poorly understood and mediators responsible for anoikis have not been well characterized. Here, we demonstrate that reactive oxygen species (ROS) produced through the involvement of the small GTPase Rac-1 upon integrin engagement exert a mandatory role in transducing a pro-survival signal that ensures that cells escape from anoikis. In particular, we show that ROS are responsible for the redox-mediated activation of Src that trans-phosphorylates epidermal growth factor receptor (EGFR) in a ligand-independent manner. The redox-dependent phosphorylation of EGFR activates both extracellular signal-regulated protein kinase and Akt downstream signalling pathways, culminating in degradation of the pro-apoptotic protein Bim. Hence, our results shed new light on the mechanism granting the adhesion-dependent antiapoptotic effect, highlighting a fundamental role of ROS-mediated Src regulation in ensuring anoikis protection.

Cell Death and Differentiation (2008) 15, 867-878; doi:10.1038/cdd.2008.3; published online 8 February 2008

Cell survival depends on multiple convergent inputs activated by growth factors and by cell adhesion to neighbouring cells and extracellular matrix (ECM) components. In non-transformed cells, the loss of cell-matrix contact triggers a particular type of apoptosis called anoikis. This process is important for maintaining tissue homoeostasis and plays an essential role in the prevention of dissemination of cells to inappropriate sites, most notably during the metastatic process. ${ }^{1}$ Several studies have shown that anoikis is regulated by the $\mathrm{Bcl}-2$ family of proteins and involves the activation of caspases following the mitochondrial outer membrane permeabilization that permits the release of proapoptotic factors such as cytochrome $c .^{2}$ Proteins belonging to the BH3-only family (Bad, Bim, Bmf and Bid) play an important role in anoikis induction, acting as sensors of cellular stress. They promote apoptosis by antagonizing the function of antiapoptotic $\mathrm{Bcl}-2 / \mathrm{Bcl}-\mathrm{X}_{\mathrm{L}}$ members and/or activating the function of Bax-like members. ${ }^{3}$ In adherent cells, $\mathrm{Bim}$ is sequestered in a cytoskeleton-associated motor complex. Cell detachment strongly induces its release and translocation to mitochondria, where it interacts with $\mathrm{Bcl}-\mathrm{X}_{\mathrm{L}}$ neutralizing its pro-survival function. ${ }^{4}$ It has been previously reported that epidermal growth factor receptor (EGFR) stimulation and the subsequent activation of extracellular signal-regulated protein kinases (ERKs) and of phosphatidylinositol 3-kinase (PI3K)/Akt signalling pathways suppress anoikis. ${ }^{5}$ Indeed, both ERK and Akt activation lead to Bim phosphorylation and its consequent degradation. ${ }^{6,7}$ Conversely, the loss of integrin engagement strongly increases Bim expression. ${ }^{4}$ Thus, it is widely recognized that both the negative regulation of cytoplasmic Bim by cell adhesion and EGFR signalling play a mandatory role in protection from anoikis.

Adhesion receptors not only support a physical attachment between ECM components and the cytoskeleton but they also generate an adhesion-dependent signalling platform containing a number of adaptor proteins and kinases. ${ }^{8}$ A growing body of literature indicates that integrin engagement can result in ligand-independent activation of many growth factor receptors, such as EGFR, ${ }^{9}$ insulin receptor, ${ }^{10}$ platelet-derived growth factor receptor, ${ }^{11}$ hepatocyte growth factor receptor, ${ }^{12}$ vascular endothelial growth factor receptor ${ }^{13}$ and Ron. ${ }^{14}$ Integrin to EGFR cross-talk is mediated by the tyrosine kinase Src and involves the recruitment of the adaptor protein p130Cas. ${ }^{15}$ The integrin-dependent and ligand-independent EGFR trans-phosphorylation results in ERK activation that leads to the upregulation of the antiapoptotic protein $\mathrm{Bcl}-2,{ }^{16}$ allowing the pro-survival signal elicited by cell adhesion. ${ }^{9,16}$

We previously reported that integrin engagement induces a transient burst of reactive oxygen species (ROS), which play an instrumental role in cell adhesion by promoting the proper activation of downstream signalling. ${ }^{17}$ Many proteins, such as protein tyrosine phosphatases (PTPs) and protein tyrosine kinases (PTKs), have been reported to be redox sensitive by virtue of the transient oxidation of their reactive catalytic thiols. ${ }^{18} \mathrm{Src}$ has been recognized as one of the major targets of the ROS produced upon cell adhesion, this molecule being activated by oxidation of two conserved cysteines. ${ }^{19}$

We reported here that Rac-1-dependent integrin-mediated ROS are key second messengers for the pro-survival signals

${ }^{1}$ Department of Biochemical Sciences, University of Florence, Florence, Italy and ${ }^{2}$ Center for Research, Transfer and High Education 'Study at Molecular and Clinical Level of Chronic, Inflammatory, Degenerative and Neoplastic Disorders for the Development of Novel Therapies', University of Florence, Florence, Italy

${ }^{*}$ Corresponding author: P Chiarugi, Dipartimento di Scienze Biochimiche, University of Florence, Viale Morgagni 50, Florence 50134, Italy. Tel: + 390554598343 ; Fax: + 39055459 8905; E-mail: paola.chiarugi@unifi.it

Keywords: anoikis; EGFR; Rac-1; reactive oxygen species; SRC

Abbreviations: ECM, extracellular matrix; EGFR, epidermal growth factor receptor; ERKs, extracellular signal-regulated protein kinases; FN, fibronectin; PTKs, protein tyrosine kinases; PTPs, protein tyrosine phosphatases; ROS, reactive oxygen species; TMRM, tetramethyl-rhodamine methyl-ester

Received 25.9.07; revised 17.12.07; accepted 07.1.08; Edited by M Piacentini; published online 08.2.08 
elicited by ECM-cell contact, thus protecting adherent cells from the anoikis programme. The results reported here show an involvement of Src redox regulation in mediating integrindependent EGFR trans-phosphorylation. In addition, we show that ROS-mediated phosphorylation of EGFR plays a crucial role in the activation of ERK and Akt downstream signalling pathways, culminating in ubiquitin-dependent degradation of the pro-apoptotic protein Bim.

\section{Results}

Role of ROS in adhesion-dependent protection from anoikis. We previously reported that adhesion to fibronectin (FN) gives rise to a transient burst of ROS that, by controlling integrin signalling, plays a mandatory role in cell adhesion and spreading. ${ }^{17}$ We speculated that ROS messengers could also play a role in adhesion-dependent protection from apoptosis. To confirm our hypothesis, during EGF and/or antioxidant treatments, we evaluated the percentage of apoptotic cells in suspended or adherent human ECV304 cells, a non-transformed, anchorage-dependent and contactinhibited cell model. We used $\mathrm{N}$-acetyl cysteine (NAC), which behaves as a general ROS scavenger, and nordihydroguaiaretic acid (NDGA), which inhibits 5-lipoxygenase (5-LOX), the main source of ROS produced during integrin adhesion. ${ }^{17}$ We observed that adhesion to $\mathrm{FN}$ reduces the percentage of apoptotic cells by more than $60 \%$ (Annexin $\mathrm{V}^{+} / 7-\mathrm{AAD}^{-}$, as assessed by flow cytometry) and EGF treatment further enhances this protective effect. Conversely, antioxidant treatment counteracts the protective effect exerted by cell adhesion and EGF administration, thus suggesting a crucial role of ROS in the protection from anoikis (Figure 1a). An important feature of apoptotic cells is depolarization of mitochondria and the consequent cytochrome $c$ release and caspase activation. ${ }^{20}$ We selectively stained mitochondria with tetramethyl-rhodamine methyl-ester (TMRM) dye and observed a strong reduction in mitochondrial membrane potential in antioxidant-treated cells (Figure 1b), thus confirming that ROS are key mediators in the adhesiondependent protection from apoptosis.

The role of Rac-1 small GTPase in ROS production, following both growth factor stimulation and integrin engagement, is well documented. This GTPase is involved in the production of ROS from the most important intracellular sources, namely NADPH oxidase, 5-LOX and mitochondria. ${ }^{17,21}$ To assess whether Rac- 1 is involved in the redox control of anoikis, we genetically manipulated the intracellular amount of ROS by means of overexpression of the constitutively active mutant of Rac-1, RacV12 and the dominant-negative form, RacN17. The evaluation of the ROS intracellular content by means of $\mathrm{H} 2\left(2^{\prime}, 7^{\prime}\right.$ dichlorofluorescein diacetate (DCF-DA) labelling provides evidence that overexpression of RacV12 leads to a threefold increase in ROS level with respect to mock or Rac-1wtoverexpressing cells, while RacN17 causes an opposite effect (Figure 1c). Our results show that the enrichment of ROS due to overexpression of RacV12 increases the percentage of cells that escape from anoikis both in suspended cells and in untreated or EGF-treated adherent ones, while the overexpression of the dominant-negative RacN17 leads to the opposite effect, which is an increase in the amount of apoptotic cells (Figure 1d). Altogether our data suggest that ECM-elicited protective signals are, at least in part, redox dependent.

Redox regulation of adhesion-induced ligand-independent activation of EGFR. Integrin signalling collaborates with signalling elicited by growth factor receptors in the mutual control of cell growth, survival and migration. It has been reported that integrin-dependent adhesion in epithelial cells triggers ligand-independent EGFR activation. Trans-activation of EGFR transduces downstream signalling necessary for an EGF transcriptional response, demonstrating that cooperation between cell-matrix adhesion and EGFR is necessary to achieve full biological responses. ${ }^{22}$ Moro et al. ${ }^{9}$ provided evidence that adhesion-induced EGFR phosphorylation leads to the activation of downstream signalling pathways, such as ERK, that supplement the natural ligand. Adhesion-induced ERK activation requires EGFR trans-activation and is sufficient to protect cells from apoptosis, while only ligand stimulation permits progression through the cell cycle. We therefore analysed the effect of integrin-elicited ROS signalling on EGF trans-activation during antioxidant treatments. We observed that both NAC and NDGA completely abolish adhesion-induced EGFR phosphorylation, but only decrease the ligand-elicited signal (Figure 2a). The role of ROS in EGFR ligandindependent phosphorylation was further confirmed by the genetic modulation of ROS content through the overexpression of Rac-1 mutants. In agreement with previous results, the constitutively active RacV12 leads to an enhancement of EGFR activation in response to $\mathrm{FN}$-induced adhesion, while the dominant-negative RacN17 almost completely abolishes EGFR trans-activation and also significantly reduces the response to the natural ligand (Figure $2 \mathrm{~b}$ ). To confirm that the protective

\footnotetext{
Figure 1 ROS are involved in protection from anoikis. (a) ECV304 $\left(1 \times 10^{6}\right)$ cells were serum-starved, detached and kept in suspension or seeded onto FN-coated dishes for $24 \mathrm{~h}$ in the presence of $5 \mu \mathrm{M}$ NDGA or $20 \mathrm{mM} \mathrm{NAC}$, stimulated with or without EGF (100 ng/ml). The percentage of apoptotic cells was evaluated using the Guava Nexin Kit. ${ }^{*} P<0.001$ (Adh. and Adh. + EGF) versus (Susp.) in control and (Adh. and Adh. + EGF) in NDGA- or NAC-treated samples versus the corresponding conditions in control. (b) ECV304 cells were detached and resuspended in serum-free medium or in serum-free medium containing NAC $(20 \mathrm{mM})$ or NDGA $(5 \mu \mathrm{M})$. Cells $\left(6 \times 10^{4}\right)$ were then kept in suspension or allowed to adhere to FN-coated cover slides and stimulated with or without EGF (100 ng/ml). After $24 \mathrm{~h}$, cells were labelled with TMRM $(1 \mu \mathrm{M})$ for $15 \mathrm{~min}$ at $37^{\circ} \mathrm{C}$. Mitochondrial potential was quantitated by fluorimetric analysis and a representative picture of single cells in each condition, analysed by confocal microscopy, is reported. Mitochondria with an intact $\Delta \psi_{\mathrm{m}}$ accumulated TMRM and therefore displayed a bright red fluorescence. (c) ECV304 $\left(1 \times 10^{6}\right)$ cells were transiently transfected with vectors expressing Racwt, RacV12 and RacN17. After $24 \mathrm{~h}$, ECV304 cells were detached, resuspended in serum-free medium and kept in suspension or seeded onto FN-coated dishes for $24 \mathrm{~h}$, stimulated with or without EGF (100 ng/ml). ROS intracellular content was evaluated by means of H2DCF-DA labelling. ${ }^{*} P<0.001$ versus mock at the same conditions. (d) Cells were treated as in (c). The percentage of apoptotic cells was evaluated using the Guava Nexin Kit. ${ }^{*} P<0.001$ versus mock at the same conditions. All data are representative of at least three independent experiments
} 
effect of Rac-1 on anoikis outcoming is actually due to a redox control, we evaluated the percentage of apoptotic cells in Racwt and RacV12 overexpressing ECV304 during antioxidant treatment. We observed that NAC administration strongly inhibits the protective effect exerted by cell adhesion and
EGF administration, thus suggesting that the ROS are strictly involved in the mechanism guiding the Rac-1-mediated regulation of anoikis (Figure 2c). In keeping with this observation, the adhesion-dependent EGFR trans-phosphorylation is completely abrogated in both the Racwt- and RacV12-overexpressing cells a

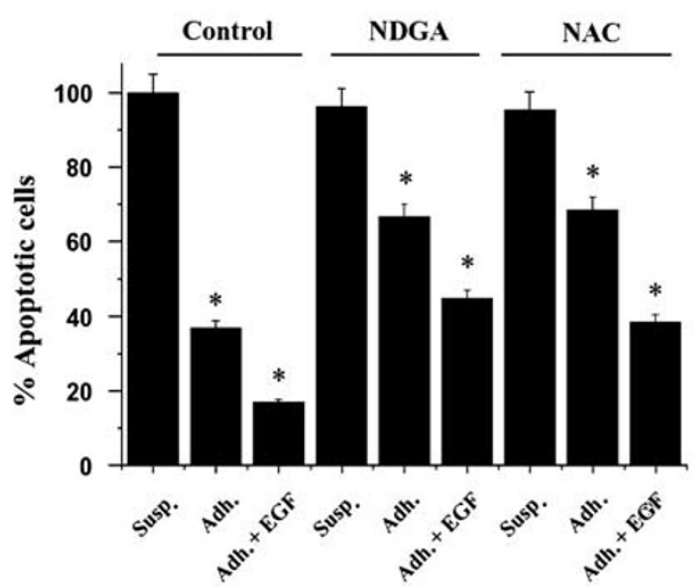

c
60
40
20
00
80
60
40
20
0

0

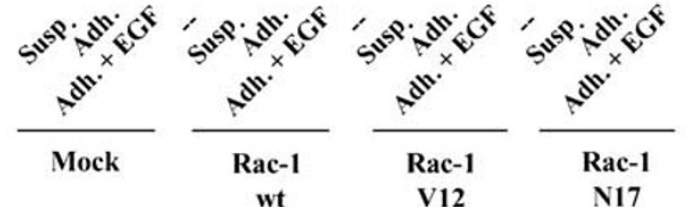

d

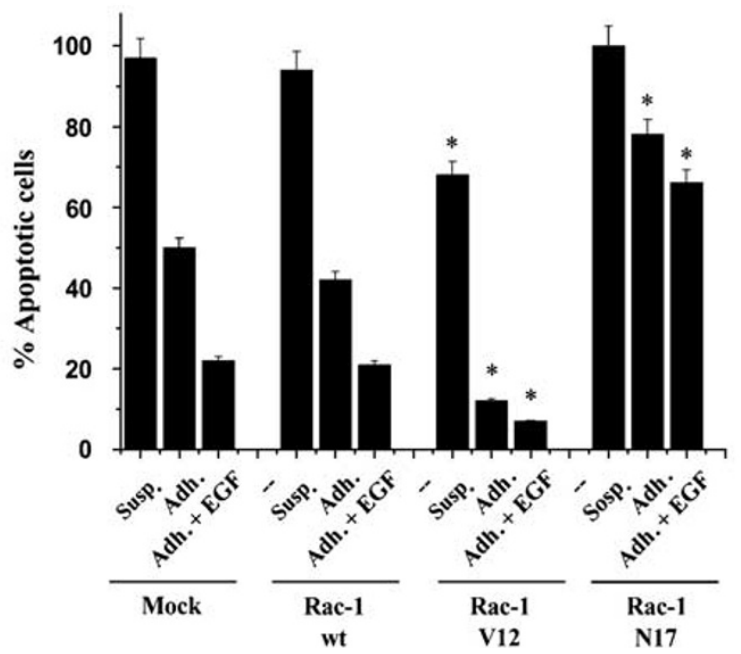

b
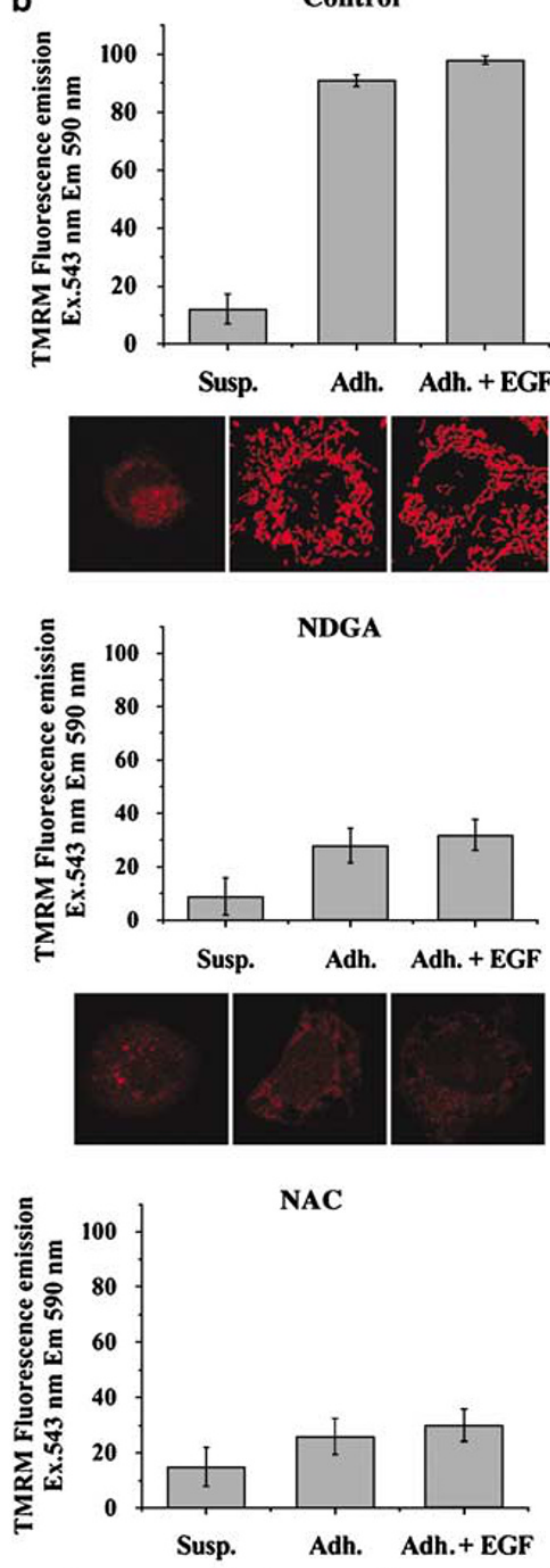
a

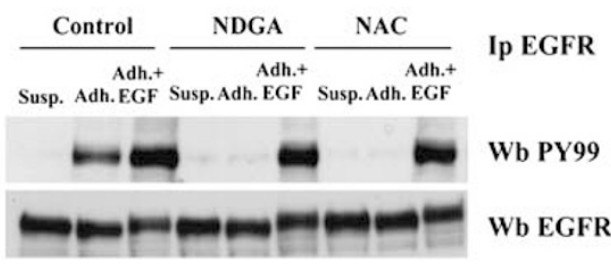

b

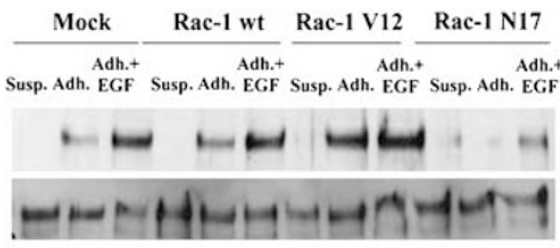

Ip EGFR

Wb PY99

Wb EGFR

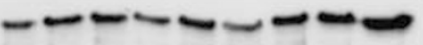

Wb Rac-1

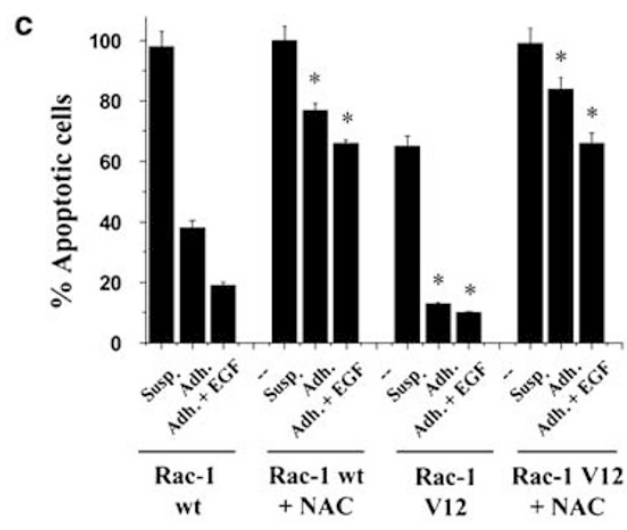

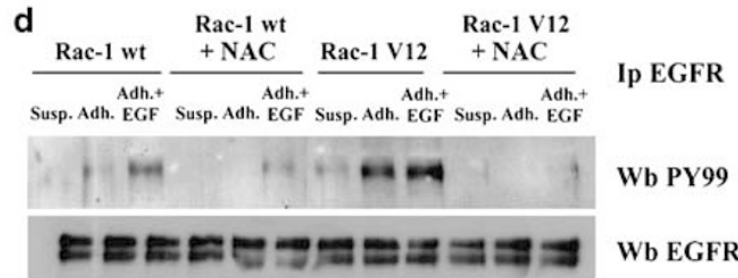

Figure 2 ROS are mediators of adhesion-induced ligand-independent activation of EGFR. (a) Serum-starved ECV304 $\left(1 \times 10^{6}\right)$ cells were detached and pretreated for $30 \mathrm{~min}$ in the presence of $5 \mu \mathrm{M} \mathrm{NDGA}$ or $20 \mathrm{mM} \mathrm{NAC}$. Cells were then maintained in suspension or seeded onto FN-coated dishes and stimulated with or without EGF (100 $\mathrm{ng} / \mathrm{ml}$ ). After $30 \mathrm{~min}$, cells were lysed and EGFR tyrosine phosphorylation was evaluated by an anti-phosphotyrosine immunoblot performed on anti-EGFR immunoprecipitates. An anti-EGFR immunoblot of the immunocomplexes was performed for normalization. (b) ECV304 $\left(1 \times 10^{6}\right)$ cells were transiently transfected for $24 \mathrm{~h}$ with Rac mutants and then treated as in (a). EGFR was immunoprecipitated from cell extracts and its phosphorylation level was evaluated with an anti-phosphotyrosine immunoblot. An anti-EGFR immunoblot was performed to normalize. The lysates $(25 \mu \mathrm{g})$ were run and immunoblotted with anti-Rac-1 antibodies to control Rac-1 overexpression level. (c) ECV304 $\left(1 \times 10^{6}\right)$ cells were transiently transfected with vectors expressing Racwt and RacV12. After $24 \mathrm{~h}, \mathrm{ECV} 304$ cells were detached, resuspended in serum-free medium and kept in suspension or seeded onto FN-coated dishes for $24 \mathrm{~h}$ with or without EGF $(100 \mathrm{ng} / \mathrm{ml})$, in the presence or absence of $20 \mathrm{mM}$ NAC. The percentage of apoptotic cells was evaluated using the Guava Nexin Kit. ${ }^{*} P<0.001$ (Rac-1wt + NAC) and (Rac-1 V12) versus (Rac-1wt) and (Rac-1 V12 + NAC) versus (Rac-1 V12) at the same conditions. (d) ECV304 $\left(1 \times 10^{6}\right)$ cells were transiently transfected for $24 \mathrm{~h}$ with Racwt and RacV12 and serum starved for additional $24 \mathrm{~h}$. Cells were then detached, pretreated for 30 min with $20 \mathrm{mM} \mathrm{NAC}$ and then treated as in (a). Both Racwt and RacV12 were overexpressed about 10-fold over the Rac-1 endogenous level observed in the untransfected cells (data not shown). All data are representative of at least three independent experiments

in response to antioxidant administration (Figure 2d). From these results, we conclude that EGFR trans-activation is a redox-mediated process dependent on the activation of the small GTPase Rac-1.

To confirm that the redox signalling engaged by Rac- 1 is upstream to EGFR-mediated protection from anoikis, we evaluated the percentage of apoptotic cells in suspended or adherent ECV304 cells upon treatment with the selective EGFR inhibitor, AG1478. We observed that both in Racwt and in RacV12-transfected cells, AG1478 administration strongly inhibits the protective effect conferred by cell adhesion (Supplementary Figure 1A) and almost completely abrogates the integrin-induced EGFR trans-phosphorylation (Supplementary Figure 1B). Taken together, these data highlight the redox-mediated EGFR trans-activation in the adhesiondependent protection from anoikis.

Adhesion-induced activation of both ERK and Akt signalling is redox dependent and regulates Bim expression. Several pathways within the cell transduce pro-survival signals that allow cells to counteract apoptotic stimuli and to escape from cell death. The ERK and the PI3K/ Akt signalling pathways are among the best characterized signals activated upon integrin and/or EGFR stimulation. ${ }^{23}$ Importantly, several studies indicate an essential role of both the ERK and the PI3K/Akt pathways in conferring cell resistance to anoikis. ${ }^{24}$ Indeed, ERK activation has been shown to influence detachment-induced apoptotic machinery by inhibiting the pro-apoptotic activity of the BH3-only protein Bim. ERKs specifically phosphorylate the isoform BimEL, thus promoting its ubiquitination and proteosomal degradation. ${ }^{25}$ Recently, Qi et al. ${ }^{7}$ demonstrated a similar role of Akt in phosphorylating and inhibiting BimEL function, thereby promoting cell survival. The key role of both PI3K/Akt and ERK pathways in conferring protection from anoikis of ECV304 cells is confirmed by the ability of both LY294002 and U0126, inhibiting PI3K and MEK1/2 activity, respectively, to prevent the integrin-dependent cell survival (Supplementary Figure 2). On the basis of this scenario, we first analysed the dependence of both these EGFR downstream pro-survival signals on intracellular ROS level modulation (Figure $3 a$ and b). We observed that ROS removal by means of antioxidant treatments leads to a strong decrease in the phosphorylation level of ERK and Akt. According to previous data, the positive modulation of ROS content by RacV12 overexpression enhanced both ERK and Akt activation, while a significant inhibition of both these pathways is evidenced in RacN17overexpressing cells (Figure $3 c$ and $d$ ). As a consequence, we assessed the effect of antioxidant treatments or overexpression of Rac-1 mutants on the amount of Bim, a 
a

$\frac{\text { Control }}{\text { Adh.+ }} \frac{\text { NDGA }}{\text { Adh.+ }} \frac{\text { NAC }}{\text { Adh.+ }}$

Susp. Adh. EGF Susp. Adh. EGF Susp. Adh. EGF

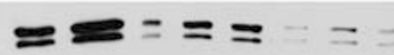

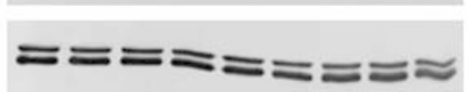

Wb p-ERK1/2

Wb ERK1/2

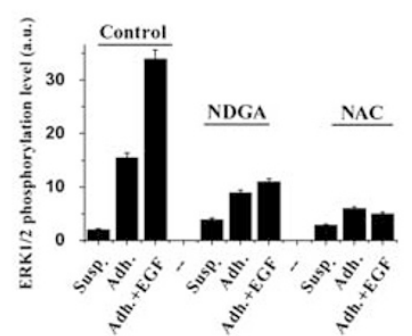

C

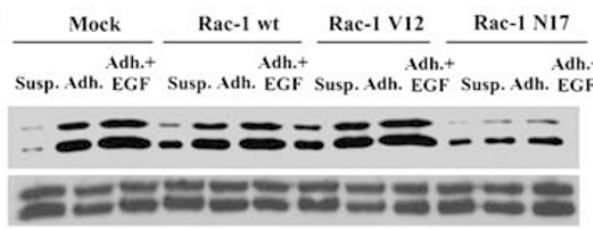

Wb p-ERK1/2

Wb ERK1/2

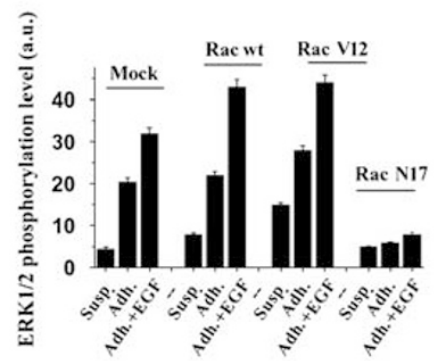

e

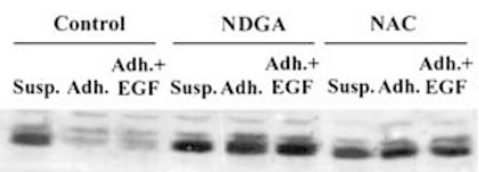

Wb Bim

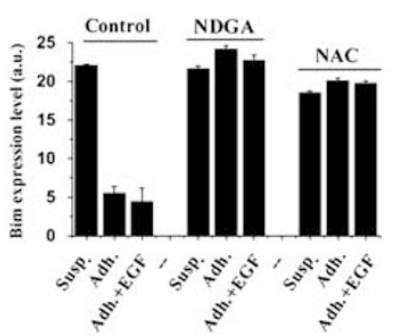

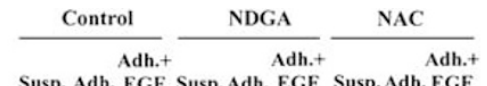

Susp. Adh. EGF Susp. Adh. EGF Susp. Adh. EGF

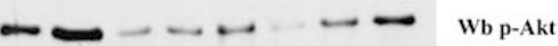

ablat

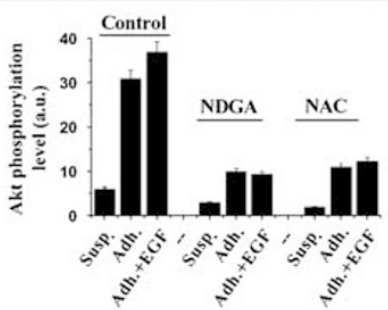

d

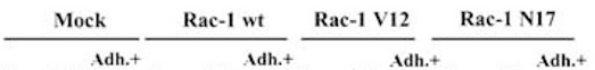

Adh.+
Susp. Adh. EGF Susp. Adh. EGF Susp. Adh. EGF Susp. Adh. EGF
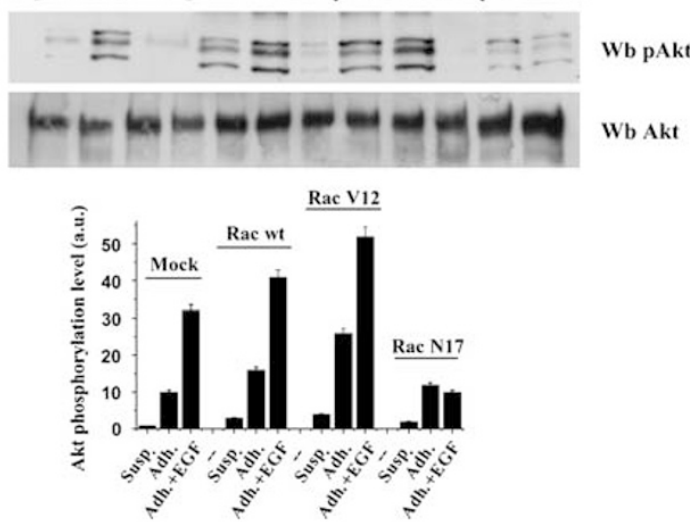

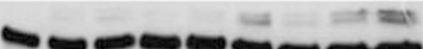

Wb Rac-1

f $\frac{\text { Mock }}{\text { Susp. Adh. EGF. }+ \text { Susp. Adh. EGF }+ \text { Susp. Adh. EGF }_{\text {Adh. }}} \frac{\text { Rasp. Adh. EGF }}{\text { Sdh. }}$
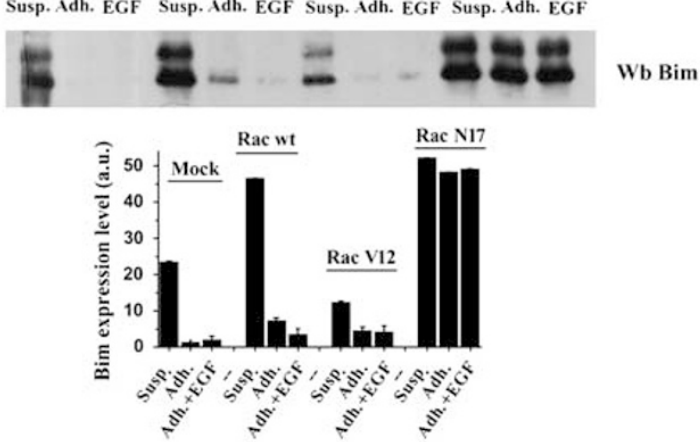

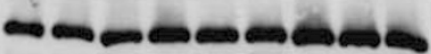

Wb Rac-1

Figure 3 Adhesion-induced activation of ERK and Akt signalling is redox dependent and regulates Bim expression. (a, b) ECV304 $\left(1 \times 10^{6}\right)$ cells were serum-starved, detached and kept in suspension or seeded onto FN-coated dishes in the presence of $5 \mu \mathrm{M} \mathrm{NDGA}$ or $20 \mathrm{mM}$ NAC, with or without EGF stimulation (100 ng/ml). After $24 \mathrm{~h}$, $25 \mu \mathrm{g}$ of total cell lysates was loaded to perform an anti-phospho-ERK and an anti-ERK immunoblot (a) and an anti-phospho-Akt and an anti-Akt immunoblot (b), respectively. (c, d) ECV304 $\left(1 \times 10^{6}\right)$ cells were transiently transfected for $24 \mathrm{~h}$ with Rac-1 mutants and then treated as previously described. The lysates were used to detect the phosphorylation level of ERK (c) and Akt (d), respectively. An anti-Rac-1 immunoblot was performed to control the amount of the overexpressed proteins. (e) ECV304 cells were treated as in (a). After $24 \mathrm{~h}$, cells were lysed and a western blot analysis was performed to detect Bim level. (f) ECV304 cells were transfected and treated as in (c). After $24 \mathrm{~h}$, cell lysates were used to evaluate Bim expression level. The amount of overexpressed Rac mutants was assessed by an anti-Rac-1 immunoblot. For all experiments $(\mathrm{a}-\mathrm{f})$, the bar graphs obtained with data from densitometry analysis of replicate experiments plotted relative to loading controls are shown. The data shown are representative of five others with similar results 
known downstream effector of both ERK- and Akt-mediated pro-apoptotic pathways. As shown in Figure $3 e$ and $\mathrm{f}$, Bim intracellular content strongly decreases after $24 \mathrm{~h}$ of integrindependent adhesion with or without EGF administration or in cells overexpressing RacV12, in strict association with ERK and Akt activation. On the contrary, antioxidant treatments or RacN17 overexpression completely prevent adhesiondependent Bim downregulation and preserve a significantly high amount of Bim from degradation. These data suggest that when ROS are removed or their production is abolished,

a

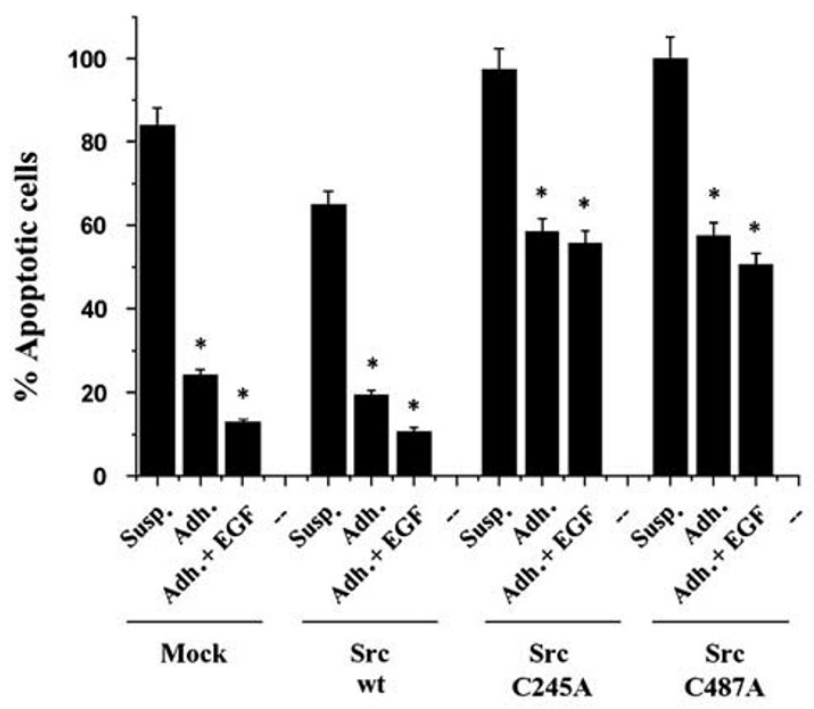

b
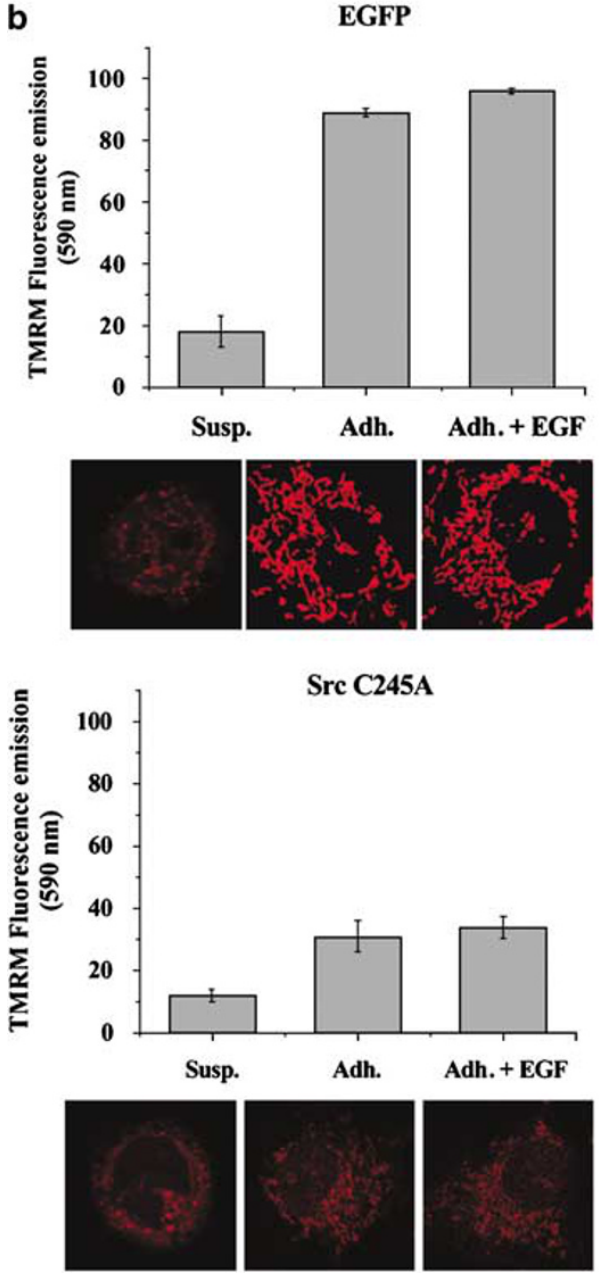

Sre wt
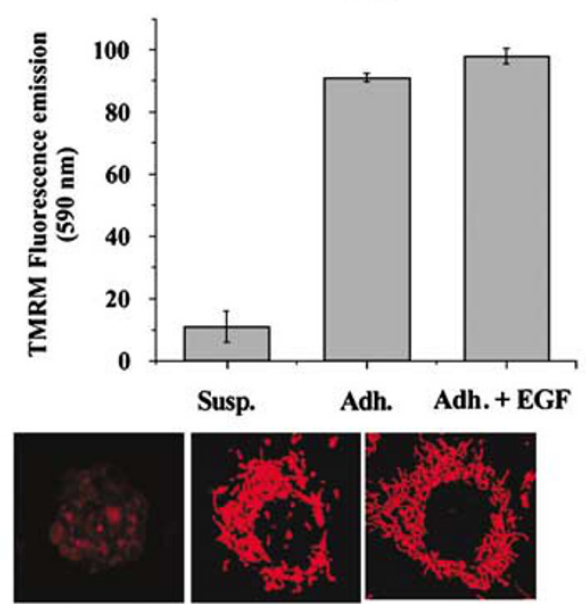

Src C487A

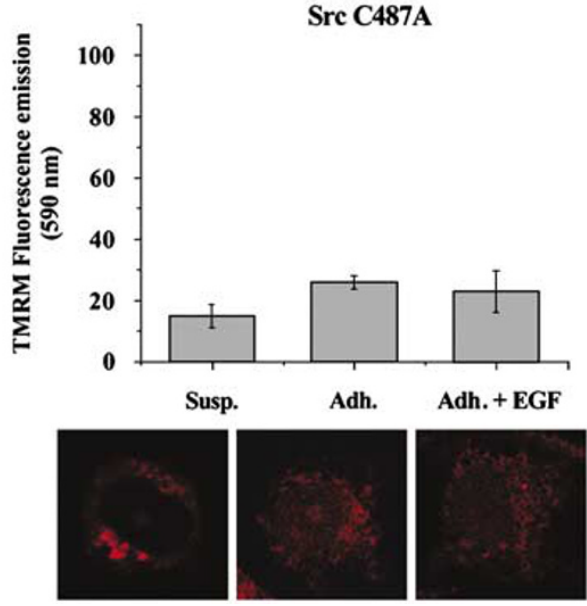


the synergistic antiapoptotic signal derived from activation of EGFR and integrins is ineffective and Bim levels remain high. Hence, in keeping with the cytofluorimetric data, the adhesion-dependent protection from anoikis is linked to the presence of ROS and likely transduced through ERK- and Akt-mediated regulation of Bim intracellular level.

Redox regulation of Src kinase is involved in the prevention of detachment-induced anoikis. Redox signalling that follows integrin engagement to ECM components leads to the oxidation of many intracellular targets such as PTPs, PTKs, and cytoskeletal protein such as $\beta$-actin whose activity is regulated by this redox modification. ${ }^{26}$ In a previous article, we provided evidence that $\mathrm{c}-\mathrm{Src}$ is one of the targets of integrin-elicited ROS. This oxidation, which involves two cysteine residues, namely C245 and C487, leads to enhancement of Src activity and to upregulation of downstream signalling activated by Src. ${ }^{19}$ In addition, Src has been indicated as responsible for the cross-talk between EGFR and integrins. In particular, integrin-mediated adhesion induces the assembly of a macromolecular complex containing c-Src and p130Cas and leads to phosphorylation of specific EGFR tyrosine residues. $^{15}$ These data allow us to assume that the effect exerted by ROS on ECM-induced protection from apoptosis could be due to their ability to influence Src activity through oxidation. The cytofluorimetric analysis of apoptotic cells reveals that in ECV304 cells overexpressing the redoxinsensitive mutant Src C245A and Src C487A, there is a substantial increase in the percentage of apoptotic cells both in adherent and EGF-stimulated cells (Figure 4a). Accordingly, mitochondrial potential evaluated by TMRM staining is reduced in cells that overexpress the redoxinsensitive Src mutants (Figure 4b), suggesting that the prevention of redox-mediated Src activation suppresses the adhesion-dependent protection from apoptosis. Altogether our results show that the antiapoptotic signal elicited by integrin engagement depends on a redox-based mechanism in which Src kinase plays a pivotal role and underlies the importance of the redox regulation of this kinase in integrindependent protection from anoikis.

Redox control of Src activity is involved in EGFR transactivation. Having assessed the importance of Src redox regulation in adhesion-induced protection from apoptosis, we used the same tools, that is, the redox-insensitive mutants Src C245A and Src C487A, to evaluate the implication of Src redox regulation in the integrin-dependent trans-activation of
EGFR. The result, reported in Figure $5 \mathrm{a}$, demonstrates that the overexpression of mutants that are unable to undergo oxidation during adhesion leads to a strong decline in EGFR activation in response to ligand stimulation and to an almost complete abolishment of ligand-independent trans-activation. Similar results were obtained by evaluation of the phosphorylation level of EGFR tyrosine 845 that is known to be directly phosphorylated by Src in several environmental settings, including integrin signalling ${ }^{15,27}$ (Figure 5b). Interestingly, analysis of the amount of Src associated with EGFR indicates that in cells expressing the redox-insensitive mutants Src C245A and Src C487A, the ability to associate with the receptor is strongly impaired compared to control cells, in accordance with the significant decrease in EGFR phosphorylation level (Figure 5c). A similar inhibition of the Src-EGFR association was observed in antioxidant-treated cells (Figure $5 d$ ), confirming the central role of ROS in mediating adhesion-induced Src-dependent activation of EGFR. Hence, these findings confirm the involvement of Src in ligand-independent EGFR trans-activation and imply a mechanism in which ROS-mediated Src activation plays a central role.

ROS-dependent Src activation is essential to modulate Bim expression, through the regulation of ERK and Akt signalling. We next examined the ability of Src redoxinsensitive mutant expression to influence EGFR-mediated ERK and Akt pathway activation. As expected, the obtained results indicated that redox regulation of Src is an upstream process, not only for ligand-independent EGFR activation but also for the start of downstream signalling pathways, since neither ERK nor Akt was activated in response to adhesion to FN when redox-insensitive mutants were overexpressed (Figure $6 \mathrm{a}$ and b). In agreement with these results, Bim content in pro-survival conditions is not downregulated in cells overexpressing Src redox-insensitive mutants (Figure 6c). This finding suggests that inhibition of the detachment-induced expression of Bim requires the redoxdependent activity of Src kinase.

\section{Discussion}

The results presented in this study reveal novel molecular cross-talks between integrin redox signalling and protection from detachment-induced apoptosis. Our data lead to two major conclusions: (a) the Rac-1-dependent ROS, developed in response to ECM contact, sustain a pro-survival signal leading to degradation of the $\mathrm{BH} 3-$ only protein Bim and (b)

Figure 4 Src tyrosine kinase is involved in protection from anoikis. (a) ECV304 $\left(1 \times 10^{6}\right)$ cells were transiently transfected with plasmid vectors expressing Src wt, Src C245A and Src C487A. After $24 \mathrm{~h}, \mathrm{ECV} 304$ cells were detached, resuspended in serum-free medium and kept in suspension or seeded onto FN-coated dishes for $24 \mathrm{~h}$, stimulated with or without EGF $(100 \mathrm{ng} / \mathrm{ml})$. The percentage of apoptotic cells was evaluated using the Guava Nexin Kit. ${ }^{*} P<0.001$ (Adh. and Adh. + EGF) versus (Susp.) in control and (Adh. and Adh. + EGF) in Src C245A or Src C487A versus the corresponding conditions in control. The amount of the overexpressed proteins was similar for ECV304 cells transfected with Src wt, Src C245A and Src C487A, respectively (data not shown). (b) ECV304 cells were co-transfected with the Src mutants (as in (a)) and with the reporter protein EGFP (enhanced green fluorescent protein) for $24 \mathrm{~h}$. ECV304 cells were then detached, resuspended in serum-free medium and $6 \times 10^{4}$ cells were kept in suspension or allowed to adhere to FN-coated cover slides and stimulated with or without EGF (100 ng/ml). After additional $24 \mathrm{~h}$, cells were labelled with TMRM $(1 \mu \mathrm{M})$ for $15 \mathrm{~min}$ at $37^{\circ} \mathrm{C}$. Mitochondrial potential was quantitated by fluorimetric analysis and a representative picture of single EGFP-positive cells in each condition, analysed by confocal microscopy, is reported. Mitochondria with an intact $\Delta \psi_{\mathrm{m}}$ accumulated TMRM and therefore displayed a bright red fluorescence. All data are representative of at least three independent experiments 
a

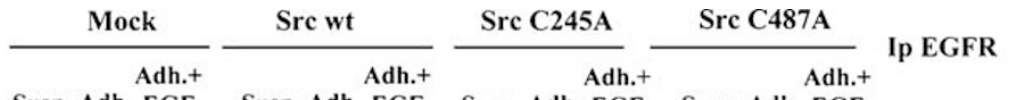

Susp. Adh. EGF Susp. Adh. EGF Susp. Adh. EGF Susp. Adh. EGF

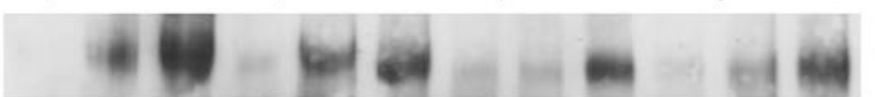

Wb PY99

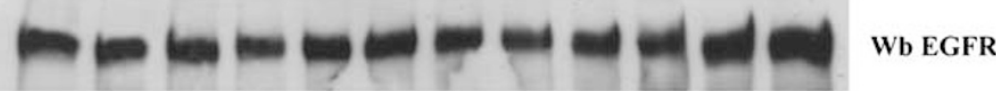

b

$\frac{\text { Mock }}{\text { Adh. }+} \frac{\text { Sre wt }}{\text { Adh.+ }} \frac{\text { Src C245A }}{\text { Adh.+ }} \frac{\text { Src C487A }}{\text { Adh. }+}$

Susp. Adh. EGF Susp. Adh. EGF Susp. Adh. EGF Susp. Adh. EGF

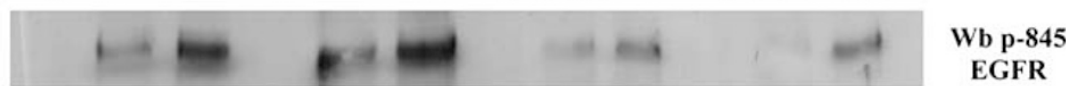

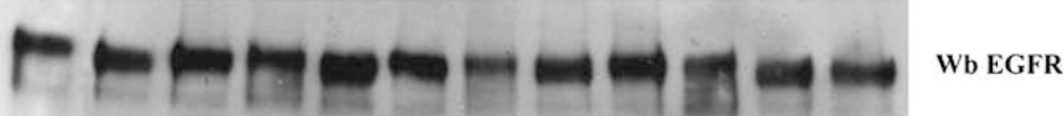

C

$\frac{\text { Mock }}{\text { Adh. }+} \frac{\text { Src wt }}{\text { Adh. }+} \frac{\text { Src C245A }}{\text { Adh. }+} \frac{\text { Src C487A }}{\text { Adh. }+}$ Ip EGFR
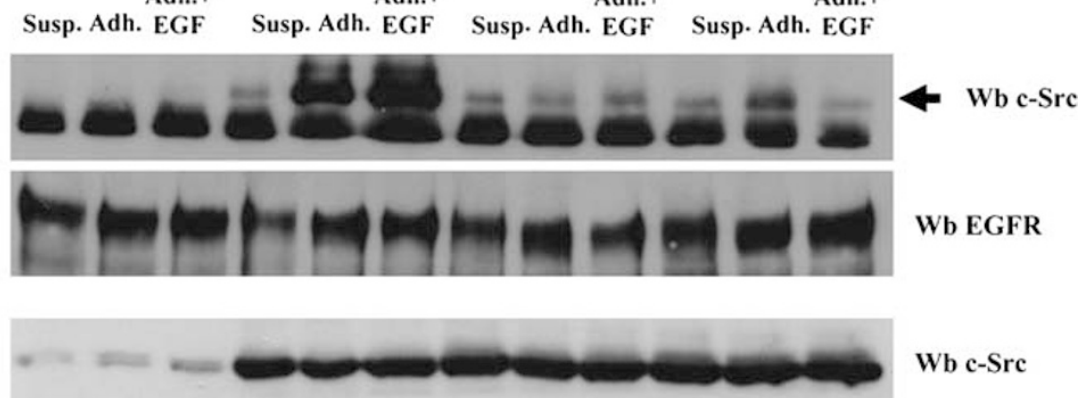

d

$\frac{\text { Control }}{\text { Adh. }+} \frac{\text { NDGA }}{\text { Adh. }+} \frac{\text { NAC }}{\text { Adh.+ }}$ Ip EGFR

Susp. Adh. EGF Susp. Adh. EGF Susp.Adh. EGF

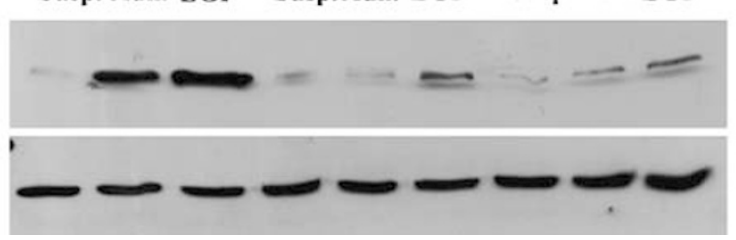

Wb c-Src

Wb EGFR

Figure 5 Redox-dependent activation of Src is critical for adhesion-induced ligand-independent activation of EGFR. (a) ECV304 $\left(1 \times 10^{6}\right)$ cells were transiently transfected with plasmid vectors expressing Src wt, Src C245A and Src C487A. After $24 \mathrm{~h}$, cells were serum starved for an additional $24 \mathrm{~h}$. Cells were then detached and maintained in suspension or seeded onto FN-coated dishes and stimulated with or without EGF (100 ng/ml). After $30 \mathrm{~min}$, cells were lysed and EGFR tyrosine phosphorylation was evaluated by an anti-phosphotyrosine immunoblot performed on anti-EGFR immunoprecipitates. An anti-EGFR immunoblot was used for normalization. (b) Cells were treated as in (a), except that $25 \mu \mathrm{g}$ of total cell lysates was loaded to perform an anti-pY845 EGFR and an anti-EGFR immunoblot used for normalization. (c) Cells were transfected and treated as previously described in (a). At $30 \mathrm{~min}$ after plating, cells were lysed and an anti-Src immunoblot was performed on anti-EGFR immunoprecipitates to evaluate the amount of Src associated with EGFR. A western blot with anti-EGFR antibodies was used for normalization. An anti-Src immunoblot was performed to check the amount of the overexpressed proteins. (d) Serum-starved ECV304 cells were detached and pretreated for 30 min with $5 \mu \mathrm{M}$ NDGA or $20 \mathrm{mM}$ NAC. Cells were then maintained in suspension or seeded onto FN-coated dishes and stimulated with or without EGF (100 ng/ml). After $30 \mathrm{~min}$, cells were lysed and the anti-EGFR immunocomplexes were subjected to an anti-Src immunoblot and an anti-EGFR immunoblot for normalization. The presented data are representative of three others with similar results

redox-sensitive Src tyrosine kinase is the central player in the cross-talk between ECM contact and the generation of the pro-survival signal, acting through ligand-independent activation of EGFR and thus sustaining ERK and Akt signals (Figure 7).
Apoptosis induced by loss of matrix attachment, a phenomenon termed anoikis, ${ }^{2}$ is a common event in untransformed adherent cells, such as epithelial, ${ }^{28}$ endothelia| ${ }^{29}$ and some fibroblastoid cell lines. ${ }^{5}$ Reliance on ECM contact for cell survival is vital to prevent improper expansion 
a

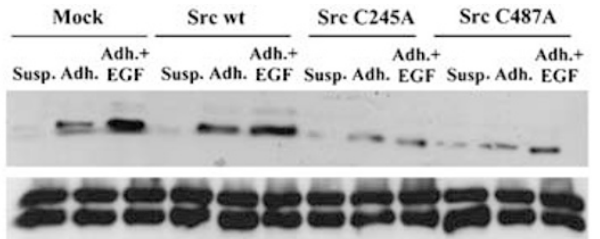

Wb p-ERK1/2

Wb ERK1/2

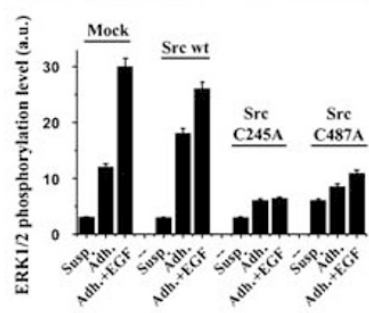

b

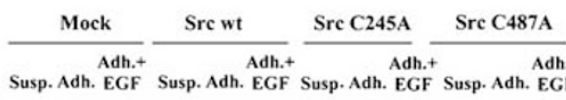

Susp. Adh. EGF Susp. Adh. EGF Susp. Adh. EGF Susp. Adh. EGF
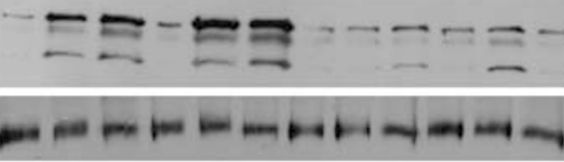

Wb p-Akt

Wb Akt

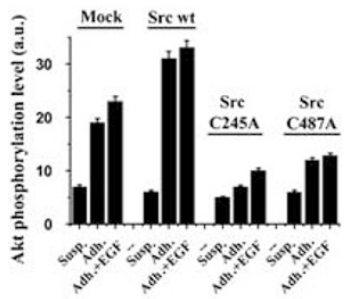

C

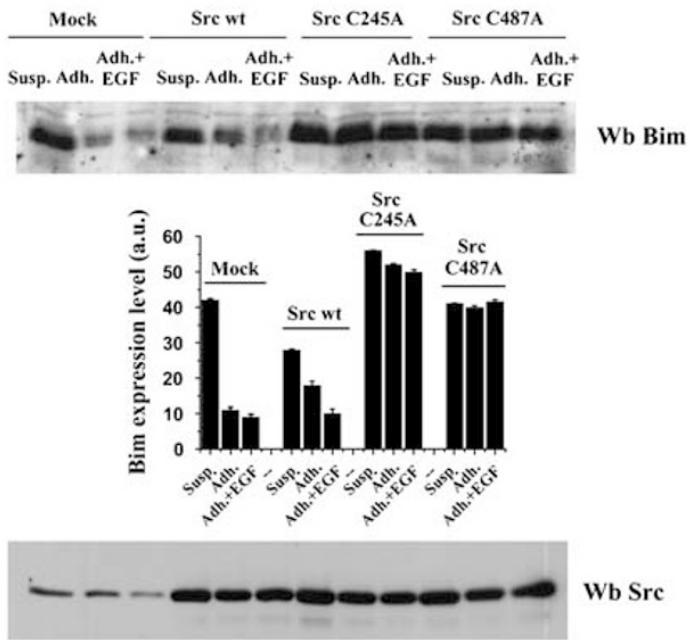

Figure 6 Redox regulation of Src is involved in regulation of survival pathways. $\left(\right.$ a, b) ECV304 $\left(1 \times 10^{6}\right)$ cells were transiently transfected for $24 \mathrm{~h}$ with plasmid vectors expressing Src wt, Src C245A and Src C487A and then detached and kept in suspension or seeded onto $\mathrm{FN}$-coated dishes in serum-free medium, with or without EGF stimulation ( $100 \mathrm{ng} / \mathrm{ml})$. After $24 \mathrm{~h}, 25 \mu \mathrm{g}$ of total cell lysates was loaded to perform an anti-phospho-ERK and an anti-ERK immunoblot (a) or an antiphospho-Akt and an anti-Akt immunoblot (b), respectively. (c) ECV304 cells were transfected and treated as in $(\mathbf{a}, \mathbf{b})$. After $24 \mathrm{~h}$, cell lysates were used to evaluate Bim expression levels by means of an anti-Bim immunoblot. The amount of overexpressed Src mutants was assessed by an anti-Src immunoblot. For all experiments $(\mathbf{a}, \mathbf{c})$, the bar graphs obtained with data from densitometry analysis of replicate experiments plotted relative to loading controls are shown. All reported experiments are representative of three others with similar results and metastatic spread of anchorage-independent populations of normal epithelial cells. Normal cells need to adhere to the matrix to progress through the mid- $\mathrm{G}_{1}$ phase of the cell cycle after mitogen treatment. ${ }^{30}$ Several signal transduction pathways have been shown so far to modulate anoikis sensitivity, including Raf-ERK, PI3K-Akt and Shc signalling. 2,5,7,9,28 Besides these known and accepted mediators of survival pathways, our data now include the small GTPase Rac-1 and its downstream signalling mediators ROS among those molecules involved in the protection of normal cells from anoikis. Although activation of Rac-1 through integrin engagement has been broadly reported, ${ }^{17,21}$ the link of this signalling pathway to cell survival and inhibition of apoptosis is a novel contribution.

Up to now ROS have been widely recognized as key second messengers during growth factor and cytokine stimulation, as well as during cell adhesion and spreading. These molecules have been reported to exert a signalling role in growth factor-stimulated proliferation as well as in the regulation of cytoskeleton reorganization and cell motility, mainly through the direct oxidation and/or indirect influence on adhesion or cytoskeletal proteins, such as Src kinase, $\beta$-actin, focal adhesion kinase or several PTPs. ${ }^{18}$ Cell proliferation of non-transformed cells is conditioned to the concomitant presence of at least three permissive routes: activation of proliferation, activation of cytoskeletal motility and adhesion, and inhibition of the constitutive apoptotic machinery. The present findings contribute to the general idea of ROS as mediators of all features of anchorage-dependent cell growth, adding to the control of cell proliferation and cell adhesion through redox-sensitive pathways, ${ }^{17-19}$ the protection from apoptosis induced by ECM detachment. In this way, ROS emerge as wide regulators of the overall progress of anchorage-dependent cell proliferation.

The key role of ROS in the protection of cells from anoikis is further strengthened by the demonstration that these messengers specifically exert their function during the spreading and acquisition of cell shape processes. It has been reported that integrin-elicited ROS are mainly produced during late adhesion to ECM, in strict concomitance with the achievement of the spread cell shape. ${ }^{17}$ In contrast, the production of oxidants is dispensable during the early phases of ECM contact. In accordance with these findings, all cytoskeletal proteins that have been involved in redox signalling, including the kinase Src, reach the maximum of oxidation and regulation of activity during late adhesion and the execution of cell spreading. In keeping with these observations, simple adhesion to ECM alone is not sufficient to provide a survival signal. Indeed, cell spreading and shape can profoundly affect the switch between proliferation and apoptosis, independently of the type of ECM and integrin used for attachment. ${ }^{31}$ In several cell types, the survival granted by ECM is conditioned by $3 D$ architecture and the achievement of a full spread cell cytoskeleton, ${ }^{32}$ thus suggesting that cell survival is dependent on the mechanical forces sustaining cell shape and tissue architecture.

Our findings demonstrate that EGFR conveys survival signals to adhering epithelial cells, which delay apoptotic death triggered by loss of matrix interaction. This observation is in strong agreement with several recent reports describing 


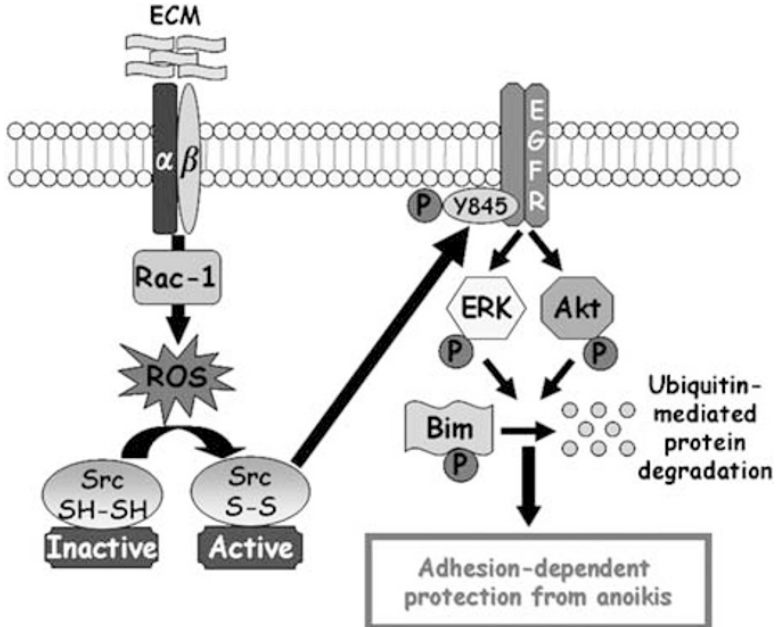

Figure 7 Proposed model for the redox regulation of adhesion-dependent protection from anoikis. During cell spreading, integrin activation through ECM-cell contact induces a significant increase in ROS intracellular level, dependent on the activity of the small GTPase Rac-1. Tyrosine kinase Src, one of the main targets of intracellular ROS, is oxidized and fully activated, allowing the specific ligandindependent phosphorylation (on Tyr 845) and activation of EGFR. The consequent activation of the ERK and Akt signalling pathways leads to the phosphorylationdependent degradation of the pro-apoptotic protein Bim and ultimately to inhibition of the apoptotic process

the key role of EGFR-dependent protection from anoikis in lung fibroblasts, ${ }^{5}$ in mammary epithelial cells or epidermal keratinocytes. $^{33}$ The kinase Src has already been implicated in resistance to apoptosis induced by ECM detachment. In particular, Src has causally been linked to ligand-independent EGFR activation in response to integrin ligation. ${ }^{15}$ In addition, survival value has been attributed to Src in the transient protection from apoptosis during initial detachment-induced pro-apoptotic events. Indeed, the loss of attachment of epithelial cells to basal membrane has been shown to rapidly trigger reversible pro-apoptotic events, from which the cells can recover if they reattach within a certain period. A transient increase in Src activity, driving a PI3K and ERK survival signal, has been shown to contribute to this transient protection of epithelial cells from apoptosis. ${ }^{34}$ In addition, altered Src activity protects human lung adenocarcinoma cells from anoikis, suggesting that the detachment-induced Src activation in tumour cells compensates for the loss of cell survival signals caused by disruption of cell-ECM interactions and contributes to anoikis resistance of tumour cells. ${ }^{35}$ Although specific redox regulation of Src during cell detachment has not been reported, a dramatic rise in ROS content coincides with endothelial cell detachment, ${ }^{36}$ thus suggesting a possible modulation of Src in these circumstances. In this context, we now propose that the specific role of Src activity during protection from apoptosis signalling is mainly redoxbased. The elimination of integrin-mediated ROS signalling, either through antioxidant/scavenger treatments or by dominant-negative Rac-1 expression, completely suppresses the ability of Src kinase to trans-activate EGFR and therefore to generate signalling, transduced by ERK and Akt, thereby suppressing Bim-mediated anoikis progression. We have already reported that integrin-induced Src activation is mainly driven by an early redox-independent phase, concomitant with first contact with ECM proteins, and by a second large redox-dependent phase, concomitant with the achievement of the spread cell shape and the full organization of the cytoskeleton architecture. ${ }^{19}$ These observations strongly suggest that the redox-independent activity of Src kinase elicited through integrin ligation is largely inadequate to sustain the survival signal, which is mainly carried out by late redox-dependent Src activation in response to achievement of the final cell architecture.

Our results on protection from apoptosis of normal epithelial cells, implying the involvement of a redox-sensitive protein widely known as a powerful oncoprotein such as Src kinase, shed new light on the critical role of Src in anchorageindependent survival of epithelial cells, guiding them towards metastatic spread. Previous data showed that Src redox regulation is mandatory for both the growth factor- and anchorage-independent growth induced by Src oncoproteins, such as v-Src and SrcY527F. ${ }^{19}$ In keeping with these observations, the protection of cells displaying constitutive activated EGFR from anoikis may have particular relevance to diseases in which deregulated production of ROS and expression of the EGFR, or both, are commonly observed, including wound healing, ${ }^{37}$ hyperproliferative skin diseases ${ }^{38}$ and advanced epithelial malignancies. ${ }^{39}$ All these diseases are characterized by survival of epithelial cells in conditions of suboptimal matrix interaction and/or by increased expression or activation of EGFR or ROS production. Indeed, increased and/or deregulated ROS production or a state of oxidative stress have been reportedly correlated with hyperproliferative disorders, such as cancer and psoriasis. ${ }^{40}$ In these pathophysiological settings, the deregulation of the redox pathways converging on Src and EGFR may help transformed cells to elude the innate apoptotic response to the abolishment of signals started by cell-ECM contact, sustaining ectopic anchorage-independent cancer cell growth.

\section{Materials and Methods}

Materials. Unless specified, all reagents were obtained from Sigma. ECV304, gifted by Paola Defilippi (University of Turin, Italy), represents a cell line in transition from an endothelial to an epithelial cell phenotype. ${ }^{41}$ All antibodies were from Santa Cruz Biotechnology, except for the anti-phospho-ERK which was from Cell Signalling Technology, the anti-Rac-1 which was from BD and the anti-ERK1/2 antibodies which were from Upstate Biotechnology. Human EGF was from Peprotech TMRM and DCF-DA was from Molecular Probes. The selective inhibitor of EGFR, AG1478, the specific inhibitor of MEK1/2, U0126 and the PI3K inhibitor LY294002, were from Calbiochem. PVDF was from Millipore. The Guava Nexin ${ }^{T M}$ kit was from Guava Technologies Inc.

Cell culture and protein overexpression. ECV304 cells were cultured in DMEM containing $10 \%$ fetal calf serum in $5 \% \mathrm{CO}_{2}$ humidified atmosphere. For transfection experiments, ECV304 cells were transiently transfected using Gene Jammer (Stratagene), as described by the manufacturer. The eukaryotic vectors pEGFP C-1-Racwt, -RacV12 and -RacN17 were a gift from Kozo Kaibuchi (Nagoya University, Japan). The eukaryotic expression vectors pSG5-Src wt and those encoding the redox-insensitive mutants Src C245A and Src C487A have been previously described. ${ }^{19}$ At $24 \mathrm{~h}$ after transfection, cells were recovered for analysis.

Detachment-induced anoikis assay. Serum-starved $1 \times 10^{6}$ ECV304 cells were detached with $2.5 \mathrm{mM}$ EDTA, washed in PBS and collected in serum-free medium. Cells were then maintained in suspension or directly seeded onto precoated culture dishes, treated overnight with $10 \mu \mathrm{g} / \mathrm{ml}$ human FN. Control cells were kept in suspension by plating them onto dishes pretreated with $1 \mathrm{mg} / \mathrm{ml}$ of bovine serum albumin in culture medium, thus preventing adhesion to the dish. For 
the experiments using antioxidant compounds, cells were resuspended in serumfree medium containing NAC $(20 \mathrm{mM})$ or NDGA $(5 \mu \mathrm{M})$ and kept in suspension for $30 \mathrm{~min}$ before plating. After $24 \mathrm{~h}$ at $37^{\circ} \mathrm{C}$, cells were analysed for the activation of the different signalling pathways.

TMRM staining and imaging. For mitochondria visualization in living cells, ECV304 cells treated as previously described were stained for $15 \mathrm{~min}$ at $37^{\circ} \mathrm{C}$ with $1 \mu \mathrm{M}$ TMRM. Loading of TMRM in metabolically active mitochondria is driven by mitochondrial membrane potential that is well maintained by healthy living cells. The disruption of this membrane potential causes an abrupt decrease in mitochondrial fluorescence that is a distinctive feature of programmed cell death. This potentiometric dye (excitation $543 \mathrm{~nm}$, emission $590 \mathrm{~nm}$ ) was evaluated by confocal microscopy (Leica SP5) and quantitated by fluorimetric assay (FluoroSkan Ascent FL).

Immunoprecipitation and western blot analysis. ECV304 $\left(1 \times 10^{6}\right)$ cells derived from our experimental conditions were lysed for $20 \mathrm{~min}$ on ice in $500 \mu \mathrm{l}$ of RIPA lysis buffer (50 mM Tris- $\mathrm{HCl}$, pH 7.5, $150 \mathrm{mM} \mathrm{NaCl}, 1 \%$ Triton X-100, $2 \mathrm{mM}$ EGTA, $1 \mathrm{mM}$ sodium orthovanadate, $1 \mathrm{mM}$ phenyl-methanesulphonyl-fluoride, $10 \mu \mathrm{g} / \mathrm{ml}$ aprotinin, $10 \mu \mathrm{g} / \mathrm{ml}$ leupeptin). Lysates were clarified by centrifugation and immunoprecipitated for $4 \mathrm{~h}$ at $4{ }^{\circ} \mathrm{C}$ with $1-2 \mu \mathrm{g}$ of the specific antibodies. Immune complexes were collected on protein A Sepharose, separated by SDS-PAGE and transferred onto nitrocellulose. Immunoblots were incubated in $3 \%$ bovine serum albumin, $10 \mathrm{mM}$ Tris-HCl pH 7.5, $1 \mathrm{mM}$ EDTA and $0.1 \%$ Tween-20, for $1 \mathrm{~h}$ at room temperature, probed first with specific antibodies and then with secondary antibodies.

Flow cytometric analysis of apoptotic cell death. The percentage of cells undergoing apoptosis was assayed by the Guava Nexin Kit, according to the manufacturer's instructions. ECV304 $\left(1 \times 10^{5}\right)$ cells were stained with phycoerythrin-conjugated Annexin-V (Annexin-V-PE) and Nexin 7 -aminoactinomycin D (7-AAD) in cold $1 \times$ Nexin Buffer in a $50 \mu$ reaction volume. After incubation for $20 \mathrm{~min}$ on ice, samples were diluted with cold Nexin buffer and analysed by a Guava Personal Cytometer (Guava Technologies). The analyser threshold was adjusted on the flow cytometer channel to exclude most of the subcellular debris to reduce the background noise. To quantify cells displaying phosphatidylserine translocation on the cell plasma membrane, we determined those Annexin-V-PE-positive cells that were 7-AAD negative. As 7-AAD only binds DNA to those cells having a non-intact plasma membrane (due both to disruption during detaching and necrosis by the treatments), Annexin-V-PE-stained cells that were 7-AAD negative were considered apoptotic.

Assay of intracellular ROS. Intracellular production of $\mathrm{H}_{2} \mathrm{O}_{2}$ was assayed as previously described. ${ }^{17}$ At 3 min before the end of the incubation time, DCF-DA was added to a final concentration of $5 \mu \mathrm{M}$. Cells were lysed in $1 \mathrm{ml}$ of RIPA buffer and analysed immediately by fluorescence analysis using a Perkin Elmer Fluorescence Spectrophotometer 650-10S equipped with a Xenon Power Supply (excitation $488 \mathrm{~nm}$, emission $510 \mathrm{~nm}$ ).

Statistical analysis. Data are presented as means \pm S.D. from at least three experiments. Analysis of densitometry was performed using Quantity One Software (Bio-Rad). Results were normalized versus control expression levels. Statistical analysis of the data was performed by Student's $t$-test. $P$-values $\leq 0.05$ were considered statistically significant.

Acknowledgements. This study was supported by the Italian Association for Cancer Research (AIRC), by the Ministero della Università e Ricerca Scientifica e Tecnologica (MIUR-PRIN 2004), by the Progetto TRESOR (Regione Toscana), by the Cassa di Risparmio di Firenze and by the Consorzio Interuniversitario Biotecnologie $(\mathrm{ClB})$. We thank Paolo Cirri and Paola Defilippi for helpful discussion.

1. Frisch SM, Screaton RA. Anoikis mechanisms. Curr Opin Cell Biol 2001; 13: 555-562.

2. Gilmore AP. Anoikis. Cell Death Differ 2005; 12 (Suppl 2): 1473-1477.

3. Cheng EH, Wei MC, Weiler S, Flavell RA, Mak TW, Lindsten T et al. BCL-2, BCL-X(L) sequester $\mathrm{BH} 3$ domain-only molecules preventing $\mathrm{BAX}$ - and $\mathrm{BAK}$-mediated mitochondrial apoptosis. Mol Cell 2001; 8: 705-711.
4. Reginato MJ, Mills KR, Paulus JK, Lynch DK, Sgroi DC, Debnath J et al. Integrins and EGFR coordinately regulate the pro-apoptotic protein Bim to prevent anoikis. Nat Cell Biol 2003; 5 : 733-740.

5. Le Gall M, Chambard JC, Breittmayer JP, Grall D, Pouyssegur J, Obberghen-Schilling E. The p42/p44 MAP kinase pathway prevents apoptosis induced by anchorage and serum removal. Mol Biol Cell 2000; 11: 1103-1112.

6. Ley R, Ewings KE, Hadfield K, Howes E, Balmanno K, Cook SJ. Extracellular signalregulated kinases $1 / 2$ are serum-stimulated 'Bim(EL) kinases' that bind to the $\mathrm{BH} 3$-only protein Bim(EL) causing its phosphorylation and turnover. J Biol Chem 2004; 279: $8837-8847$

7. Qi XJ, Wildey GM, Howe PH. Evidence that Ser87 of BimEL is phosphorylated by Akt and regulates BimEL apoptotic function. J Biol Chem 2006; 281: 813-823.

8. Giancotti FG. Complexity and specificity of integrin signalling. Nat Cell Biol 2000; 2: E13-E14.

9. Moro $L$, Venturino $M$, Bozzo $C$, Silengo $L$, Altruda $F$, Beguinot $L$ et al. Integrins induce activation of EGF receptor: role in MAP kinase induction and adhesion-dependent cell survival. EMBO J 1998; 17: 6622-6632.

10. Schneller M, Vuori K, Ruoslahti E. Alphavbeta3 integrin associates with activated insulin and PDGFbeta receptors and potentiates the biological activity of PDGF. EMBO J 1997; 16: $5600-5607$.

11. Sundberg C, Rubin K. Stimulation of beta1 integrins on fibroblasts induces PDGF independent tyrosine phosphorylation of PDGF beta-receptors. J Cell Biol 1996; 132: 741-752.

12. Wang CZ, Hsu YM, Tang MJ. Function of discoidin domain receptor I in HGF-induced branching tubulogenesis of MDCK cells in collagen gel. J Cell Physiol 2005; 203: 295-304.

13. Soldi R, Mitola S, Strasly M, Defilippi P, Tarone G, Bussolino F. Role of alphavbeta3 integrin in the activation of vascular endothelial growth factor receptor-2. EMBO J 1999; 18: 882-892.

14. Danilkovitch-Miagkova A, Angeloni D, Skeel A, Donley S, Lerman M, Leonard EJ. Integrinmediated RON growth factor receptor phosphorylation requires tyrosine kinase activity of both the receptor and c-Src. J Biol Chem 2000; 275: 14783-14786.

15. Moro L, Dolce L, Cabodi S, Bergatto E, Erba EB, Smeriglio M et al. Integrin-induced epidermal growth factor (EGF) receptor activation requires c-Src and p130Cas and leads to phosphorylation of specific EGF receptor tyrosines. J Biol Chem 2002; 277: 9405-9414.

16. Shen $\mathrm{X}$, Kramer RH. Adhesion-mediated squamous cell carcinoma survival through ligandindependent activation of epidermal growth factor receptor. Am J Pathol 2004; 165: 1315-1329.

17. Chiarugi $P$, Pani G, Giannoni E, Taddei L, Colavitti R, Raugei G et al. Reactive oxygen species as essential mediators of cell adhesion: the oxidative inhibition of a FAK tyrosine phosphatase is required for cell adhesion. J Cell Biol 2003; 161: 933-944.

18. Chiarugi P, Giannoni E. Anchorage-dependent cell growth: tyrosine kinases and phosphatases meet redox regulation. Antioxid Redox Signal 2005; 7: 578-592.

19. Giannoni E, Buricchi F, Raugei G, Ramponi G, Chiarugi P. Intracellular reactive oxygen species activate Src tyrosine kinase during cell adhesion and anchorage-dependent cell growth. Mol Cell Biol 2005; 25: 6391-6403.

20. Kuwana T, Newmeyer DD. Bcl-2-family proteins and the role of mitochondria in apoptosis. Curr Opin Cell Biol 2003; 15: 691-699.

21. Taddei ML, Parri M, Mello T, Catalano A, Levine AD, Raugei G et al. Integrin-mediated cell adhesion and spreading engage different sources of reactive oxygen species. Antioxid Redox Signal 2007; 9: 469-481.

22. Cabodi S, Moro L, Bergatto E, Boeri EE, Di Stefano P, Turco E et al. Integrin regulation of epidermal growth factor (EGF) receptor and of EGF-dependent responses. Biochem Soc Trans 2004; 32 (Pt 3): 438-442.

23. Jorissen RN, Walker F, Pouliot N, Garrett TP, Ward CW, Burgess AW. Epidermal growth factor receptor: mechanisms of activation and signalling. Exp Cell Res 2003; 284: 31-53.

24. Zeng Q, Chen S, You Z, Yang F, Carey TE, Saims D et al. Hepatocyte growth factor inhibits anoikis in head and neck squamous cell carcinoma cells by activation of ERK and Akt signaling independent of NFkappa B. J Biol Chem 2002; 277: 25203-25208.

25. Ley R, Ewings KE, Hadfield K, Cook SJ. Regulatory phosphorylation of Bim: sorting out the ERK from the JNK. Cell Death Differ 2005; 12: 1008-1014.

26. Chiarugi $P$, Fiaschi T. Redox signalling in anchorage-dependent cell growth. Cell Signal 2007; 19: 672-682.

27. Biscardi JS, Maa MC, Tice DA, Cox ME, Leu TH, Parsons SJ. c-Src-mediated phosphorylation of the epidermal growth factor receptor on Tyr845 and Tyr1101 is associated with modulation of receptor function. J Biol Chem 1999; 274: 8335-8343.

28. Rytomaa M, Lehmann K, Downward J. Matrix detachment induces caspase-dependent cytochrome $c$ release from mitochondria: inhibition by PKB/Akt but not Raf signalling. Oncogene 2000; 19: 4461-4468.

29. Meredith Jr JE, Fazeli B, Schwartz MA. The extracellular matrix as a cell survival factor. Mol Biol Cell 1993; 4: 953-961.

30. Assoian RK. Control of the G1 phase cyclin-dependent kinases by mitogenic growth factors and the extracellular matrix. Cytokine Growth Factor Rev 1997; 8: 165-170.

31. Chen CS, Mrksich M, Huang S, Whitesides GM, Ingber DE. Geometric control of cell life and death. Science 1997; 276: 1425-1428

32. Weaver VM, Lelievre S, Lakins JN, Chrenek MA, Jones JC, Giancotti F et al. Beta4 integrin-dependent formation of polarized three-dimensional architecture confers 
resistance to apoptosis in normal and malignant mammary epithelium. Cancer Cell 2002; 2: 205-216.

33. Quadros MR, Peruzzi F, Kari C, Rodeck U. Complex regulation of signal transducers and activators of transcription 3 activation in normal and malignant keratinocytes. Cancer Res 2004; 64: 3934-3939

34. Loza-Coll MA, Perera S, Shi W, Filmus J. A transient increase in the activity of Src-family kinases induced by cell detachment delays anoikis of intestinal epithelial cells. Oncogene 2005; 24: 1727-1737.

35. Wei $\mathrm{L}$, Yang $\mathrm{Y}$, Zhang $\mathrm{X}, \mathrm{Yu} \mathrm{Q}$. Altered regulation of Src upon cell detachment protects human lung adenocarcinoma cells from anoikis. Oncogene 2004; 23: 9052-9061.

36. Li AE, Ito H, Rovira II, Kim KS, Takeda K, Yu ZY et al. A role for reactive oxygen species in endothelial cell anoikis. Circ Res 1999; 85: 304-310.
37. Marikovsky M, Breuing K, Liu PY, Eriksson E, Higashiyama S, Farber P et al. Appearance of heparin-binding EGF-like growth factor in wound fluid as a response to injury. Proc Nat Acad Sci USA 1993; 90: 3889-3893.

38. Cook PW, Pittelkow MR, Keeble WW, Graves-Deal R, Coffey Jr RJ, Shipley GD. Amphiregulin messenger RNA is elevated in psoriatic epidermis and gastrointestinal carcinomas. Cancer Res 1992; 52: 3224-3227.

39. Ferraro D, Corso S, Fasano E, Panieri E, Santangelo R, Borrello S et al. Pro-metastatic signaling by c-Met through RAC-1 and reactive oxygen species (ROS). Oncogene 2006 25: 3689-3698.

40. Bickers DR, Athar M. Oxidative stress in the pathogenesis of skin disease. $J$ Invest Dermatol 2006; 126: 2565-2575.

41. Kiessling F, Kartenbeck J, Haller C. Cell-cell contacts in the human cell line ECV304 exhibit both endothelial and epithelial characteristics. Cell Tissue Res 1999; 297: 131-140.

Supplementary Information accompanies the paper on Cell Death and Differentiation website (http://www.nature.com/cdd) 